Running head: PERSONALITY CHANGE AND WELL-BEING

\title{
Is Personality Fixed? Personality Changes as Much as "Variable" Economic Factors and More Strongly Predicts Changes to Life Satisfaction
}

\author{
Christopher J. Boyce \\ School of Psychological Sciences, University of Manchester, UK \\ chrisopher.boyce@manchester.ac.uk
}

\author{
Alex M. Wood \\ School of Psychological Sciences, University of Manchester, UK \\ $\underline{\text { alex.wood@manchester.ac.uk }}$ \\ Nattavudh Powdthavee \\ London School of Economics and the University of Melbourne \\ n.powdthavee@gmail.com
}

Correspondence concerning this article should be addressed to Christopher J Boyce, School of Psychological Sciences, University of Manchester, Oxford Road, Manchester, M13 9PL, UK; email: christopher.boyce@ manchester.ac.uk.

Acknowledgements: The Economic and Social Research Council (PTA-026-27-2665)

provided research support. This paper uses unit record data from the Household, Income and Labour Dynamics in Australia (HILDA) Survey. The HILDA Project was initiated and is funded by the Australian Government Department of Families, Housing, Community Services and Indigenous Affairs (FaHCSIA) and is managed by the Melbourne Institute of Applied Economic and Social Research (Melbourne Institute). The findings and views reported in this paper, however, are those of the author and should not be attributed to either FaHCSIA or the Melbourne Institute. 
Running head: PERSONALITY CHANGE AND WELL-BEING

Is Personality Fixed? Personality Changes as Much as "Variable" Economic Factors and More Strongly Predicts Changes to Life Satisfaction 


\begin{abstract}
Personality is the strongest and most consistent cross-sectional predictor of high subjective well-being. Less predictive economic factors, such as higher income or improved job status, are often the focus of applied subjective well-being research due to a perception that they can change whereas personality cannot. As such there has been limited investigation into personality change and how such changes might bring about higher well-being. In a longitudinal analysis of 8625 individuals we examine Big Five personality measures at two time points to determine whether an individual's personality changes and also the extent to which changes in personality can predict changes in life satisfaction. We find that personality changes at least as much as economic factors and relates much more strongly to changes in life satisfaction. Our results therefore suggest that personality can change and that such change is important and meaningful. Our findings may help inform policy debate over how best to help individuals and nations improve their well-being.
\end{abstract}

Keywords: PERSONALITY CHANGE, BIG FIVE, SUBJECTIVE WELL-BEING, LIFE SATISFACTION, FIXED EFFECTS, INCOME 
Personality change and well-being 4

\section{Is personality fixed? Personality changes as much as "variable" economic factors and more strongly predicts changes to life satisfaction}

The extent to which personality changes is a central question for fields interested in quality of life. Personality - comprising the psychological aspect of a person that is carried from one situation to another - is one of the strongest and most consistent predictors of subjective well-being (Diener \& Lucas, 1999; Ferrer-i-Carbonell \& Frijters, 2004; Lykken \& Tellegen, 1996). For example, people's measurable personality traits have been shown to account for at least $35 \%$ of the between-person variance in life satisfaction ${ }^{1}$ (Wood, Joseph, \& Maltby, 2008), and this is typically much higher than the explanation of demographic characteristics such as an individual's income (4\%), employment status (4\%), and marital status (1-4\%) (Anand et al., 2009; Argyle, 1999; Gutierrez, Jimenez, Hernandez, \& Puente, 2005; Lucas \& Dyrenforth, 2006). However, whilst there is academic value in knowing that personality is an important predictor of high well-being, from a purely applied perspective personality may only be interesting if it is something that changes (Ferrer-i-Carbonell, 2005). If, for example, income changed but personality did not, from an interventional perspective it would be preferable to understand the process of income growth and its relation to wellbeing, even though income is a much smaller predictor of high well-being overall. Analogically, although the biggest predictors of longevity may be fixed, and changeable factors such as eating healthily only have a small impact on longevity, it is still good public policy to encourage people to eat healthily. Thus, the question of whether personality change takes place is therefore central to discussions regarding improvements to well-being and creating positive environments that enable individuals to grow and develop themselves may even be seen as a legitimate public policy goal.

\footnotetext{
${ }^{1}$ Throughout this study we refer to both subjective well-being and life satisfaction. Our use of subjective wellbeing refers to a the general body of research that has attempted to understand an array of self-report measures of well-being that includes, for example, moment to moment feelings and emotions (e.g. positive and negative affect), mental and physical health and cognitive evaluations of various domains of one's life. Our discussion of life satisfaction, however, refers to a specific component of subjective well-being that represents a cognitive evaluation of one's life overall. Life satisfaction is the particular aspect of subjective well-being used in the subsequent analysis.
} 
Within economics there is an increasing interest in personality - often conceptualized as non-cognitive skills - due to the predictive value of personality in, for example, wage determination (Groves, 2005; Mueller \& Plug, 2006; Nyhus \& Pons, 2005; Semykina \& Linz, 2007), behavior within ultimatum games (Schmitt, Shupp, Swope, \& Mayer, 2008; Swope, Cadigan, Schmitt, \& Shupp, 2008), the degree to which individuals share knowledge with colleagues (Matzler, Renzl, Muller, Herting, \& Mooradian, 2008), job matching (Winkelmann \& Winkelmann, 2008), and the accumulation of wealth (Ameriks, Caplin, \& Leahy, 2003; Ameriks, Caplin, Leahy, \& Tyler, 2007). Personality has also been shown to predict the well-being response following important life events such as unemployment (Boyce, Wood, \& Brown, 2010), disability (Boyce \& Wood, 2011b), widowhood (Pai \& Carr, 2010), and income increases (Boyce \& Wood, 2011a). A greater empirical and theoretical understanding of personality in economics could have substantial benefits (Borghans, Duckworth, Heckman, \& ter Weel, 2008). However, there remains a widespread assumption within economics that personality is essentially fixed and unchangeable (Ferrer-iCarbonell \& Frijters, 2004).

The fixed personality assumption is problematic for two reasons. First, it reduces the interest of personality to applied economists and public policy-makers. Even if personality is predictive, for example, of labour force status and occupational behaviour, but is unchanging and fixed, it is not a useful target for macro- or micro- level intervention. Second, the assumption of much standard microeconometric analysis is reliant upon personality being fixed and unchanging. For example, the relationship between income and subjective wellbeing, or the influence of wages on labour supply, are commonly investiagated using a fixed effects regression analysis. Such an analysis exploits longitudinal data to isolate withinperson changes in the predictor across time and associates these changes with within-person changes in outcomes. Since this technique removes all between person variance, any nonchanging between person characteristics (e.g., gender) cannot confound the results and therefore do not directly need to be added as a covariates. Currently, within economics such 
fixed effects analysis are assumed to remove the effect of non-changing personality, an assumption that would be brought into question if personality were found to meaningfully change over time.

Within psychology the attitude towards personality change is more mixed. The traditional persepctive in psychology is that personality is relatively enduring and stable essentially personality has been thought of as fixed, particulalrly after the age of 30, where it has been said to be "set like plaster" (Costa \& McCrae, 1980, 1988). Any apparent change across time was attributed to measurement error. Later studies have since suggested that personality is instead set like "soft" plaster, in that personality does change, albeit only marginally, beyond 30 and across the entire life cycle (Srivastava, John, Gosling, \& Potter, 2003). Some of this research is problematic to interpret, as it has been based on crosssectional differences in the mean level of personality traits across age groups, which could represent either real change or simply cohort effects (where, for example, people at a certain age only appear to have different personality profiles due to events that historically happened to their cohort in youth). More recent longitudinal research, however, suggests that personality change does take place, with the same people giving different responses to personality questionnaires on different occasions (e.g. Helson, Jones, \& Kwan, 2002; Lucas \& Donnellan, 2011; Roberts, Walton, \& Viechtbauer, 2006a; Roberts, Wood, \& Caspi, 2008) and as such a relatively broad consensus that personality does change has developed (Costa \& McCrae, 2006; Roberts, Walton, \& Viechtbauer, 2006b). However, it is not always clear from this research whether such change is meaningful, or simply represents error in the form of inconsistent responding.

In the present research using the Household, Income and Labour Dynamics in Australia we examine not only whether personality changes but also whether this change is meaningfully related to well-being. The Big Five model of personality represents the dominant personality model within psychology and suggests that there are, at the highest level of abstraction, five dimensions to an individual's personality; openness-to-experience, 
conscientiousness, extroversion, agreeableness and neuroticism (Goldberg, 1993). The crosssectional relationship between these personality traits and well-being has been carefully examined before (e.g. DeNeve \& Cooper, 1998; Steel, Schmidt, \& Shultz, 2008).

Neuroticism, for example, represents the tendency for someone to respond with negative emotions to threatening situations, frustration, and loss. Neuroticism is a strong predictor of various mental and physical health disorders (Lahey, 2009). Extrovert individuals tend to experience more positive affect and that this could be due to greater social participation (Srivastava, Angelo, \& Vallereux, 2008). Positive affect can also help individuals deal with stress (Folkman \& Moskowitz, 2000) and help individuals feel that life is meaningful (King, Hicks, Krull, \& Del Gaiso, 2006). Due to the strong links with positive and negative affect both extroversion and neuroticism are considered to have a direct relationship with wellbeing and as such are often the strongest predictors.

The other traits, agreeableness, conscientiousness and openness, tend to orientate individuals towards circumstances that are beneficial for well-being and are therefore conceived of as having weaker instrumental (or indirect) influences on well-being. For example, agreeableness indicates individuals who are pleasant, warm and likeable and tend to act in accordance with other people's interests (Graziano \& Tobin, 2009). Agreeableness predicts better quality relationships (Berry, Willingham, \& Thayer, 2000) and agreeable individuals tend to have pro-social motives (Graziano, Habashi, Sheese, \& Tobin, 2007). Conscientiousness indicates that individuals are goal orientated (Barrick, Mount, \& Strauss, 1993), have high levels of motivation (Judge \& Ilies, 2002) and as a result are more likely to achieve (McGregor \& Little, 1998). Openness-to-experiences is the personality trait most strongly linked to aspects of intelligence (Fumham, Swami, Arteche, \& Chamorro-Premuzic, 2008) and also captures the degree to which an individual has artistic tendencies (ChamorroPremuzic, Reimers, Hsu, \& Ahmetoglu, 2009).

However, the extent to which these personality characteristics change and relate to changes in subjective well-being has not been carried out before. Specifically, using a fixed 
effects regression analysis that focuses on the associations of within-person variations over time we examine how changes in personality relate to changes in a cognitive component of subjective well-being: life satisfaction. This approach could potentially contribute to both the economic and psychological literatures in several ways. First, if personality change can be linked to change in another variable, then it would suggest that such changes are substantive rather than simply inconsistent responding. Second, it would allow a more direct comparison of the relative degree to which personality explains life satisfaction compared to economic indicators, such as income. Such a direct comparison is not currently possible, and claims of the relative predictive ability of personality on the various components of subjective wellbeing are complicated by relying on comparisons across studies with non-compatible methodologies (e.g., through comparing income effect estimates based on within-person changes and personality effect estimates based on between-person estimates). Third, this direct comparison will allow an estimate of the relative magnitude of the change in personality variables compared to the changes in variables commonly considered to be variable (e.g., income). Taken together, this research aims to show not only that personality change occurs but also that this change is meaningfully related to changes in life satisfaction. If supported, this would suggest (a) that personality itself could potentially be considered a quality of life variable (and at the aggregate level a social indicator), (b) that there may be scope for interventional research aimed at attaining personal and economic benefits from creating environments that encourage the development of positive personality traits, and (c) the fixed effects analysis of personality may form a new and preferable analytic method for psychological research.

\section{Methodology}

A standard approach within economic research to determine the relationship between time varying characteristics on the various components on subjective well-being, such as life 
satisfaction (LS), is a fixed effects estimator. A fixed effect analysis is easily performed when multiple individuals are observed across multiple time-points.

(1) $\mathrm{LS}_{\mathrm{it}}=\alpha+\mathrm{D}_{\mathrm{it}}+\beta_{\mathrm{k}} \mathrm{X}_{\mathrm{it}}+\mu_{\mathrm{i}}+\varepsilon_{\mathrm{it}}$

In equation 1 the life satisfaction of a given individual, $i$, at a given time period, $t$, is dependent upon a number of factors which include; specific regional and time period factors, $\mathrm{D}$, a series of observable time varying characteristics, $\mathrm{X}$, and individual heterogeneity that although varying across individuals is typically assumed to not vary across time, $\mu$. An understanding of how life satisfaction changes in relation to changes in time varying characteristics can only be obtained provided there are controls for all of these correlated factors. If we assume that the factors contained within $\mu$ have zero within-person variation then any changes to an individual's life satisfaction could be said to not have arisen from these non-varying factors. How should personality enter into the well-being equation? A standard approach within economic subjective well-being research is to classify personality as a component of individual heterogeneity, $\mu$, in that it varies between individuals but is the same within each individual from year to year (Ferrer-i-Carbonell \& Frijters, 2004).

Here in contrast to previous research we treat personality as a time varying characteristic, $\mathrm{X}$, and try to determine whether the within-person variation of personality predicts the within-person variation in subjective well-being. First, we carry out standard cross-sectional regressions to determine the relative importance of personality factors compared with economic variables, such as income and employment status, as correlates of life satisfaction. This will show which variables are the strongest cross-sectional predictors of higher life satisfaction. However, such a regression does not exploit the time-varying aspects of these variables and cannot determine how changes to personality might relate to changes in life satisfaction. Next, we therefore exploit the longitudinal nature of the data. In the first instance we simply compare the within-person variability of personality variables with 
demographic characteristics. We then carry out a fixed effect estimation to determine the relative importance of personality factors compared with demographic characteristics in predicting the within-person variation in life satisfaction.

\section{Data}

It is becoming more common to find large representative longitudinal data sets that contain reliable personality measures frequently used by psychologists. This has arisen in part from economists becoming more interested in personality, but also from psychologists becoming more interested in analyzing the longitudinal datasets typically used by economists. Here we use the Household, Income and Labour Dynamics in Australia (HILDA) survey which asked questions about personality based on standard Big Five questionnaires (Goldberg, 1993). Due to limited available testing time a shortened version of the Big Five scale was administered in both the 2005 and 2009 waves of HILDA. In a self-complete questionnaire survey participants were presented with 36 descriptive words (e.g. talkative, jealous, sympathetic, intellectual, orderly) and asked "how well the following words describe you". For each word participants were asked to indicate how well the word described them on a 1 to 7 scale, with 1 meaning the word "does not describe me at all" and 7 that it "describes me very well". Not all 36 items were used in the derived scales contained within HILDA that summarize the five personality factors since some of the words were found to have inadequate reliability. The personality measures in HILDA have been shown to have adequate levels of normality, construct validity, internal consistency and external correlates (Losoncz, 2009). To aid the interpretation of our results we standardized the personality scores across the entire sample to have a mean of zero and a standard deviation of one. Since the personality variables were asked in only two years we construct a two wave panel and as such we have a special case fixed effect model $(\mathrm{T}=2)$, which is equivalent to a firstdifference model. 
In all other respects the HILDA is a representative longitudinal sample of Australian households. The survey has been used in a number of subjective well-being studies (e.g. Frijters, Johnston, \& Shields, 2011; Headey \& Wooden, 2004) and the survey contains a single item life satisfaction question which asks "how satisfied are you with your life, all things considered?" Individuals chose a number from 0 to 10 , whereby higher numbers indicate higher satisfaction. Since it has been shown that there is little difference between estimating effects using cardinal or ordinal models (Ferrer-i-Carbonell \& Frijters, 2004) the life satisfaction measure is treated here as cardinal. We additionally include in our set of explanatory variables gender, age, education, annual household income, the size of the individual's household, marital and employment status. The effect that such variables, barring gender and age, have on life satisfaction is typically best understood by focusing on the within-person variation.

The 2 year balanced panel contains 8625 individuals (3947 men, 4678 women), producing 17250 individual time-point observations with the descriptive statistics shown in Table 1 . Table 1 presents life satisfaction and personality measures in their raw scores but for all the analyses life satisfaction and personality scores are standardized across the sample with a mean of zero and a standard deviation of one to give a more intuitive and meaningful interpretation. Table 2 presents a correlation matrix of life satisfaction, personality traits and demographic characteristics. Table 2 shows that the personality traits are correlated with life satisfaction and many of the demographic characteristics highlighting the need to control for personality in any subjective well-being study. At the first time point in 2005 individuals were on average 44.5 years old, with ages ranging from 15 to 93.

\section{Results}

We begin by estimating an ordinary least squares regression across our sample to illustrate the degree to which personality explains an individual's life satisfaction. Personality is considered to be the largest and most consistent predictor of subjective well-being (Diener 
\& Lucas, 1999) and this is confirmed in the life satisfaction regressions in Table 3. In the first column of Table 3 it is shown that standard demographic controls explain around $6.5 \%$ of an individual's life satisfaction, whereas personality measures alone, as shown in column 2, explain nearly $10 \%$. However, the correlation matrix in Table 2 shows that the economic indicators, such as income and employment status, are correlated with both life satisfaction and the personality measures. This highlights the importance of controlling for personality in understanding how income and employment relate to life satisfaction. The next column therefore includes both personality and the demographic controls in the pooled crosssectional regression and as expected the effect sizes reduce. The combined explanation of the standard demographic variables and personality measures is around $15 \%$ and this suggests that personality is not only an important predictor but is also additive. Neuroticism and agreeableness are the personality traits that have the strongest predicting effect and a comparison can be made with other predictive factors. For example, all things being equal, being unemployed is associated with the same amount of life satisfaction as being around 0.75 standard deviations lower in levels of neuroticism than the average, and a one percent higher income is associated with the same amount of life satisfaction as being approximately 0.01 standard deviations higher in agreeableness.

However, the conclusions that can be drawn from cross-sectional observations are somewhat limited since they do not help the understanding of how changes to personality might relate to changes in life satisfaction. When there are repeat observations of the same individuals, however, it is possible to investigate potential longitudinal relationships and begin to understand how personality and life satisfaction might co-evolve together. Personality, although a strong cross-sectional predictor of life satisfaction (DeNeve \& Cooper, 1998; Steel, et al., 2008), is typically regarded as non-changing (Ferrer-i-Carbonell \& Frijters, 2004) and under this view could not be expected to relate meaningfully to changes in life satisfaction. We examine the longitudinal patterns by first determining the extent to which personality changes over time. Table 1, in addition to showing the means and standard 
deviations of the variables used in this analysis, also displays the between- and within-person standard deviations of these variables. An examination of these standard deviations shows us the extent to which a variable varies between relative to within individuals. Plumper \& Troeger (2007) have suggested that the ratio between these two standard deviations gives a broad indication of whether the relationship of an independent variable to some dependent variable can be satisfactorily estimated using the fixed effects model. A fixed effects estimation focuses exclusively on the within-person variation and thus necessarily discards any information about the between-person variation. As a result the larger the betweenperson standard deviation is in comparison to that of the within-person standard deviation the greater the loss of information and the lower the benefit of using a fixed effect estimation.

A comparison of the ratios of the between- and within-person standard deviations across variables is a useful way in which to understand the extent to which variables change over time. Variables that are typically estimated using a fixed effect estimation, such as income or being married, have ratios of above 2 , thus suggesting that there is greater variation between individuals than within them. Unemployment, however, varies about the same within individuals as it does between them. An examination of the personality variables show that the ratio of the between and within person standard deviations are of comparable levels to the demographic characteristics, with neuroticism in particular varying about as much within individuals as it does between. This could lead to the conclusion that personality is generally stable and tends to vary much more between than within individuals. However, personality appears to be no more stable than other individual characteristics that would typically be investigated using a fixed effect estimation. Thus these early descriptive statistics imply that if the effects of income and marriage on life satisfaction are best understood by analyzing within-person variations then the same would be true for personality. In addition personality change could be correlated with changes to individual characteristics. For example, personality change may be a third variable that explains both income increases and life satisfaction increases. Therefore, not appropriately accounting for personality change in 
our model may bias the estimates of the relationship between changes to individual characteristics and life satisfaction.

In Table 4 we therefore examine how personality change influences changes to life satisfaction using fixed effect estimations. In column 1 we estimate a regression containing only demographic controls. Since personality measures are not included as explanatory variables in this model there is an implicit assumption that personality is fixed. This regression is analogous to the ordinary least squares regression carried out in the first column of Table 3, except that age and gender cannot be included as explanatory variables, and that here we are observing exclusively within-person variations. Here, we see that these demographic factors explain just over $1 \%$ of the within-person variation in life satisfaction ${ }^{2}$. The results suggest that a $1 \%$ increase in household income is associated with 0.0003 standard deviation increase in life satisfaction and becoming unemployed is associated with a drop in life satisfaction of -0.15 standard deviations. In column 2 we carry out a fixed effect regression using only the Big Five personality traits - here the implicit assumption is that all other correlated factors are fixed. The first thing to note is that the within-person variations of these personality traits explain nearly $2 \%$ of the within-person variation in life satisfaction, with both neuroticism and extroversion having particularly strong effects. The within-person variation of personality therefore explains nearly double the explanation of the demographic factors included in the regression from column 1 . Our $3^{\text {rd }}$ column extends our model by including both personality traits and demographic factors. As with the cross-sectional regressions there again appears to be an additive effect. The coefficients remain similar in magnitude and the total explanation of the within-person variation in life satisfaction rises to around 3\%. This suggests that (a) personality, traditionally considered as fixed and nonchanging, does change and (b) that the individual changes in personality are more predictive

\footnotetext{
${ }^{2} \mathrm{~A}$ low $\mathrm{R}^{2}$ is fairly typical for these variables in large representative samples (e.g. Ferrer-i-Carbonell \& Frijters, 2004).
} 
of life satisfaction changes than economic characteristics that would typically be seen as variable, such as income or employment status.

In column 4 of Table 4 we enter income as a non-logged variable. This enables us to calculate the estimated dollar values that would be necessary to achieve the same changes in life satisfaction as would a change in an individual's personality. It has become relatively commonplace within economic research into subjective well-being to attach monetary values to an array of life circumstances (Blanchflower \& Oswald, 2004; Ferrer-i-Carbonell \& van Praag, 2002; Oswald \& Powdthavee, 2008a, 2008b; Powdthavee, 2008) and can be somewhat illuminating since it enables the conversion of an effect size into a common understandable metric. For example, our results suggest that a one standard deviation change in openness to experience is associated with approximately the same change in life satisfaction as would a AUD \$61,000 ( USD \$62,000) increase in annual household income. The dollar values for one standard deviation changes in the other personality traits are as follows:

Conscientiousness - AUD \$91,000 ( USD \$92,000), Extroversion - AUD \$222,000 ( USD \$225,000), Agreeableness - AUD \$147,000 ( USD \$149,000), Neuroticism - AUD $\$ 309,000$ ( USD \$314,000). The average annual household income is around AUD \$87,000 ( USD $\$ 88,000)$ each year so these dollar values could be considered as high and therefore highlight the importance of changes to personality in the relationship with higher life satisfaction. However, it should be noted that such monetary values are based on an extrapolation beyond the range of incomes contained in HILDA and as such some caution is therefore needed. Nevertheless this further highlights that changes to personality are in any case more achievable by being within the range of the sample.

\subsection{Discussion}

There is a substantial amount of subjective well-being research that has tried to identify how changes in life circumstances might relate to changes in the quality of life. Here, we explored the importance of a changing personality. The influence of how changes to an 
individual's personality might relate to improved well-being has often been overlooked due to a prevailing view that personality is largely fixed and unchanging over time. Here, we examined whether personality truly is fixed and whether there is a relationship between changes in personality and changes in life satisfaction. We demonstrated using Australian data that personality does change and that the extent to which personality changes is comparable to other characteristics, such as income, unemployment and marital status, which are typically of applied interest because they do change. First, our cross-sectional regressions confirmed that personality is the strongest predictor of life satisfaction (Diener \& Lucas, 1999). Our longitudinal analyses, however, explored the extent to which changes to personality and life satisfaction co-occurred by assessing how the within-person variation of personality characteristics related to within-person variation in life satisfaction. We showed that personality change meaningfully predicts changes to life satisfaction and that the degree to which changes to personality predict changes to life satisfaction is nearly double the explanation of all the other demographic characteristics considered here combined. Our research has a number of implications.

First, there are broad analytical implications for both economic and psychological research. Economists are naturally interested in how economic variables influence various aspects of behavior. Heterogeneous factors, such as personality, are often viewed as inconveniences that correlate with the variables that are of real interest to economists. Under the assumption of a fixed personality it is possible to employ econometric techniques that circumvent the need to fully understand the influence of personality (Ferrer-i-Carbonell \& Frijters, 2004). However, the fixed personality assumption has not been sufficiently scrutinized and such an assumption has arisen in part out of convenience, owing to unavailable personality measures (see Boyce, 2010). Our research suggests that econometric models that do not account for personality change may be incorrectly specified. Personality change may act in part as a third variable that explains why various economic variables change together and as such by not correctly controlling for changes to personality it may be 
difficult to obtain accurate economic relationships. Our research therefore adds to the small but burgeoning literature that shows how personality measures from psychology can help answer important economic questions (e.g. Ameriks, et al., 2003; Ameriks, et al., 2007; Borghans, et al., 2008; Boyce \& Wood, 2011a, 2011b; Boyce, et al., 2010; Groves, 2005; Matzler, et al., 2008; Mueller \& Plug, 2006; Nyhus \& Pons, 2005; Schmitt, et al., 2008; Semykina \& Linz, 2007; Swope, et al., 2008; Winkelmann \& Winkelmann, 2008).

Personality psychology may have much to gain from fully investigating changes in personality, and in particular employing econometric techniques to aid this investigation. The fixed effect model, which focuses exclusively on within-person variations, as presented here, is not well known to psychologists, but could have broad importance for personality research. The analysis of the within-person variation is particularly advantageous when trying to understand how variables change together. The within-person analysis enables a researcher to discount the influence of variables that, although correlated with dependent and independent variables, are constant across time but could be immeasurable, unobservable or unknown. Such factors might include systematic biases in how individuals respond to a set of questions (measurement error), genetic influences and cognitive skills that although varying considerably between individuals may remain constant within individuals from one measurement point to the next.

Second, our findings raise the provocative possibility that personality could be viewed as a quality of life variable. Measures of well-being, since they can be changed, are often regarded as important indicators of quality of life (e.g. Diener, 2000). Since we have shown here that personality also changes then personality measures may similarly serve to indicate something about the quality of life of both individuals and societies. For example, since neuroticism predicts various mental and physical health disorders there would be clear benefits to both individuals and societies from reducing the prevalence of neuroticism (Lahey, 2009). Increases in extroversion and agreeableness may indicate community involvement and reflect a willingness to work together to form mutually beneficial solutions. 
Conscientious individuals may reflect societies that are more willing to work towards specific goals. Conscientious individuals have a tendency to live longer (Hill, Turiano, Hurd, Mroczek, \& Roberts, 2011) and are more likely to make changes to their health behavior (O'Connor, Conner, Jones, McMillan, \& Ferguson, 2009). Openness-to-experiences may indicate non-cognitive aspects of intelligence (Fumham, et al., 2008) and creativity (Chamorro-Premuzic, et al., 2009).

A third important implication of our research is that there may be greater scope for interventional research to understand how and why personality traits or non-cognitive skills might be developed. In policy the focus is often on economic factors, such as increasing income or reducing unemployment, which are believed to be important ways in which an individual might obtain higher well-being. However, our data suggests that a better way to understand how we might improve our well-being could be to focus on who we are and how we relate to the world around us. In the same way that certain environments may be more conducive for individuals to develop themselves economically other environments may be more conducive to the development of personality traits or non-cognitive skills that could further benefit an individual's life. Public policy could be useful in fostering such positive environments that help the individual to develop and grow. For example, an increase in the access and availability of mental health services to help individuals overcome neurotic tendencies could have huge benefits to both individual well-being (Boyce \& Wood, 2010) and worker productivity (Layard, 2006). It has also been shown that attributional style, the way individuals attribute cause to events, can be developed through work based training interventions and lead to greater employee well-being, job satisfaction, productivity, and turnover (Proudfoot, Corr, Guest, \& Dunn, 2009). The development of personality traits may also lead to greater personal successes in life. For example, the frequency of experiencing positive affect, which is related to extroversion, may result in success across various life domains (Lyubomirsky, King, \& Diener, 2005). Personality traits are also important for job 
search behavior (Kanfer, Wanberg, \& Kantrowitz, 2001) and certain traits are beneficial to employers and therefore attract higher wages (Bowles, Gintis, \& Osborne, 2001).

We highlighted the importance of personality change by calculating the implied change in income that would be needed to raise life satisfaction by the same amount as one standard deviation changes in each of the Big Five personality traits. In economic subjective well-being research monetary values are often place on various life events in order to give readers a sense of how important an event is for their well-being in a common metric that is easy to understand (Blanchflower \& Oswald, 2004; Ferrer-i-Carbonell \& van Praag, 2002; Oswald \& Powdthavee, 2008a, 2008b; Powdthavee, 2008). The use of monetary values, however, can also demonstrate the relative importance for well-being of specific characteristics in comparison to income (see Boyce \& Wood, 2010) and here the equivalent dollar values of changes to personality were found to be extremely high. For example, a one standard deviation change in neuroticism has a dollar value of AUD \$309,000 ( USD $\$ 314,000$ ) and suggests there could be substantial benefit in understanding personality development as a potential mechanism to higher well-being.

\subsection{Limitations}

There are several limitations to our research. An inevitable drawback of focusing on the within-person variation and not being able to isolate exogenous events is that we are unable to say anything concrete about the direction of causality. Whilst this represents a limitation of the current research, the purpose of this research was to highlight that personality does change, against a prevailing view that it does not, and importantly show that this change is meaningful. As such our study is the first to show that changes in personality relates in some way to changes in life satisfaction. It is not possible to say what the exact causal mechanism is behind these changes but by first showing that changes to personality do take place our research opens the doors for future research that can attempt to unpick the exact causal mechanism behind this strong within-person association. On a somewhat related 
issue our study is limited by the use of only two waves of personality measures. Were a greater number of waves available then it might have been possible to determine whether personality or life satisfaction changed first, and also further determine whether personality change loses predictive power in the long run.

Further, although we demonstrate that personality does change this does not necessarily mean that personality can be actively changed. Changes in personality may be triggered by certain experiences and events but could also take place due to natural maturation. It has been shown, however, that personality can change due to specific occupational experiences (Roberts, 1997; Roberts \& Bogg, 2004; Roberts, Caspi, \& Moffitt, 2003; Scollon \& Diener, 2006), relationship experiences (Neyer \& Asendorpf, 2001; Roberts \& Bogg, 2004; Roberts, Helson, \& Klohnen, 2002; Watson \& Humrichouse, 2006), the use of certain drugs (MacLean, Johnson, \& Griffiths, in press; Roberts \& Bogg, 2004), and intensive outpatient counselling (Piedmont, 2001). Such experiences are also likely to result in changes to well-being and it is possible that the influence on well-being of various experiences and events could be somewhat mediated by personality change. It would therefore be important for future research to disentangle whether increased well-being came about due to the actual experience or event itself, or instead only as a result of the change in personality that the event created. However, it is important to highlight that the explanation given by changes in personality and changes in individual characteristics appeared to be additive reducing the possibility of personality playing a mediating role. Nevertheless now that this important link to higher well-being has been established this would be an important area of investigation for future research.

A further concern is that our research relies on self report measures of both personality and subjective well-being. Not only is there likely to be some concern with self report measures in general but there may also be some concern in particular with the use of subjective measures to explain other subjective measures. However, there has been over 50 years history of the use and measurement of personality scores within psychology, which has 
suggested that such self-reports of personality are both meaningful and valid, and are distinctly different to measures of subjective well-being. For example, the initial identification of the "Big Five" traits was based on self-ratings of every personality relevant word in the dictionaries of several languages, with factor analyses consistently converging on the same five traits, suggesting a strong universality of these traits (Goldberg, 1993; McCrae \& Costa, 1997). Self-report personality measures have been shown to relate strongly to peerratings (McCrae \& Costa, 1987), objective biological functioning (O'Cleirigh, Ironson, Weiss, \& Costa, 2007; Ryff et al., 2006) and a huge range of objective occupational, social, and health behaviours (J. Hogan \& Holland, 2003; R. Hogan, 2005; Judge, Bono, Ilies, \& Gerhardt, 2002; Paunonen \& Ashton, 2001). The development of self report inventories normally involves showing that (a) the structure of responses is as expected, (b) items highly inter-correlate, $(c)$ responses are stable over time, $(\mathrm{d})$ convergence with expected outcomes (e.g., peer ratings or other known correlates), (e) responses predict future outcome (e.g., either behaviour or changes in other variables over time, (f) incremental prediction of outcome above other known predictors, and (f) a lack of association with theoretically unrelated constructs (e.g., a tendency to respond in socially desirable ways) (Clark \& Watson, 1995; Worthington \& Whittaker, 2006). In psychology, if these steps have been followed, it is assumed that the scales represent an accurate reflection of the actual personality trait being measured.

There is, however, likely to be a natural amount of overlapping variance in subjective measures due to measurement error and biased responses. The order in which questions are asked can influence responses, particularly if questions are asked quite closely together (Schwarz, Strack, \& Mai, 1991). For example, if personality were asked immediately prior to a question on life satisfaction it is possible that the response to the life satisfaction question may be heavily influenced by how an individual feels about their personality. This could result in the influence of personality on life satisfaction being overestimated. It is also possible that an individual's mood at the time of answering will influence responses 
(Schwarz \& Clore, 1983). Although it is difficult to eradicate such biases entirely in HILDA, it is important to note that this influence is somewhat mitigated since the question about life satisfaction is asked first in a face-to-face interview whilst the questions about personality are answered in a self-completion questionnaire that is administered after the face-to-face interview. Further the respondents answer the self-completion questionnaire in their own time and it is collected at a much later date which also limits the bias due to moods specific to the time and day of questioning. Some bias will no doubt always remain. Again it was not the purpose of our research to answer such questions conclusively but instead to highlight, against the prevailing view that personality does not meaningfully change, that changes to personality relate meaningfully to changes in subjective well-being.

\subsection{Conclusion}

We showed using data on 8,625 Australian individuals that personality varies at least as much as socio-economic factors that are typically considered as variable, such as income, unemployment and marital status. We then showed that these personality changes were meaningfully related to changes in life satisfaction. Personality change was found to explain nearly double the explanation the change in life satisfaction of all the other demographic characteristics considered here combined. Our research has a number of applied implications and also generates a number of important questions for future research. 


\section{References}

Ameriks, J., Caplin, A., \& Leahy, J. (2003). Wealth accumulation and the propensity to plan. Quarterly Journal of Economics, 118, 1007-1047.

Ameriks, J., Caplin, A., Leahy, J., \& Tyler, T. (2007). Measuring self-control problems. American Economic Review, 97, 966-972.

Anand, P., Hunter, G., Carter, I., Dowding, K., Guala, F., \& Van Hees, M. (2009). The development of capability indicators. Journal of Human Development and Capabilities, 10, 125-152.

Argyle, M. (1999). Causes and correlates of happiness. In D. Kahneman, E. Diener \& N. Scwarz (Eds.), Well-Being: The Foundations of Hedonic Psychology. New York: Russell Sage Foundation

Barrick, M. R., Mount, M. K., \& Strauss, J. P. (1993). Conscientiousness and performance of sales representatives - test of the mediating effects of goal-setting. Journal of Applied Psychology, 78, 715-722.

Berry, D. S., Willingham, J. K., \& Thayer, C. A. (2000). Affect and personality as predictors of conflict and closeness in young adults' friendships. Journal of Research in Personality, 34, 84-107.

Blanchflower, D. G., \& Oswald, A. J. (2004). Well-being over time in Britain and the USA. Journal of Public Economics, 88, 1359-1386.

Borghans, L., Duckworth, A. L., Heckman, J. J., \& ter Weel, B. (2008). The economics and psychology of personality traits. Journal of Human Resources, 43, 972-1059.

Bowles, S., Gintis, H., \& Osborne, M. O. (2001). Incentive-enhancing preferences: Personality, behavior, and earnings. American Economic Review, 91, 155-158.

Boyce, C. J. (2010). Understanding fixed effects in human well-being. Journal of Economic Psychology, 31, 1-16. 
Boyce, C. J., \& Wood, A. M. (2010). Money or mental health: The cost of alleviating psychological distress with monetary compensation versus psychological therapy. Health Economics, Policy and Law, 5, 509-516.

Boyce, C. J., \& Wood, A. M. (2011a). Personality and the marginal utility of income: Personality interacts with increases in household income to determine life satisfaction. Journal of Economic Behavior \& Organization, 78, 183-191.

Boyce, C. J., \& Wood, A. M. (2011b). Personality prior to disability determines adaptation: Agreeable individuals recover lost life satisfaction faster and more completely. Psychological Science, 22, 1397-1402.

Boyce, C. J., Wood, A. M., \& Brown, G. D. A. (2010). The dark side of conscientiousness: Conscientious people experience greater drops in life satisfaction following unemployment. Journal of Research in Personality, 44, 535-539.

Chamorro-Premuzic, T., Reimers, S., Hsu, A., \& Ahmetoglu, G. (2009). Who art thou? Personality predictors of artistic preferences in a large UK sample: The importance of openness. British Journal of Psychology, 100, 501-516.

Clark, L. A., \& Watson, D. (1995). Constructing validity: Basic issues in objective scale development. Psychological Assessment, 7, 309-319.

Costa, P. T., \& McCrae, R. R. (1980). Influence of extraversion and neuroticism on subjective well-being - happy and unhappy people. Journal of Personality and Social Psychology, 38, 668-678.

Costa, P. T., \& McCrae, R. R. (1988). Personality in adulthood - a 6-year longitudinal-study of self-reports and spouse ratings on the Neo Personality-Inventory. Journal of Personality and Social Psychology, 54, 853-863.

Costa, P. T., \& McCrae, R. R. (2006). Age changes in personality and their origins: Comment on Roberts, Walton, and Viechtbauer (2006). Psychological Bulletin, 132, 26-28.

DeNeve, K. M., \& Cooper, H. (1998). The happy personality: A meta-analysis of 137 personality traits and subjective well-being. Psychological Bulletin, 124, 197-229. 
Diener, E. (2000). Subjective well-being - The science of happiness and a proposal for a national index. American Psychologist, 55, 34-43.

Diener, E., \& Lucas, R. E. (1999). Personality and subjective well-being. In D. Kahneman, E. Diener \& N. Scwarz (Eds.), Well-Being: The Foundations of Hedonic Psychology. New York: Russell Sage Foundation

Ferrer-i-Carbonell, A. (2005). Income and well-being: an empirical analysis of the comparison income effect. Journal of Public Economics, 89, 997-1019.

Ferrer-i-Carbonell, A., \& Frijters, P. (2004). How important is methodology for the estimates of the determinants of happiness? Economic Journal, 114, 641-659.

Ferrer-i-Carbonell, A., \& van Praag, B. M. S. (2002). The subjective costs of health losses due to chronic diseases. An alternative model for monetary appraisal. Health Economics, 11, 709-722.

Folkman, S., \& Moskowitz, J. T. (2000). Positive affect and the other side of coping. American Psychologist, 55, 647-654.

Frijters, P., Johnston, D. W., \& Shields, M. A. (2011). Life satisfaction dynamics with quarterly life event data. Scandinavian Journal of Economics, 113, 190-211.

Fumham, A., Swami, V., Arteche, A., \& Chamorro-Premuzic, T. (2008). Cognitive ability, learning approaches and personality correlates of general knowledge. Educational Psychology, 28, 427-437.

Goldberg, L. R. (1993). The structure of phenotypic personality-traits. American Psychologist, 48, 26-34.

Graziano, W. G., Habashi, M. M., Sheese, B. E., \& Tobin, R. A. (2007). Agreeableness, empathy, and helping: A person X situation perspective. Journal of Personality and Social Psychology, 93, 583-599.

Graziano, W. G., \& Tobin, R. M. (2009). Agreeableness. In M. R. Leary \& R. H. Hoyle (Eds.), Handbook of Individual Differences in Social Behavior. New York: Guildford Press. 
Groves, M. O. (2005). How important is your personality? Labor market returns to personality for women in the US and UK. Journal of Economic Psychology, 26, 827841.

Gutierrez, J. L. G., Jimenez, B. M., Hernandez, E. G., \& Puente, C. P. (2005). Personality and subjective well-being: Big Five correlates and demographic variables. Personality and Individual Differences, 38, 1561-1569.

Headey, B., \& Wooden, M. (2004). The effects of wealth and income on subjective wellbeing and ill-being. Economic Record, 80, S24-S33.

Helson, R., Jones, C., \& Kwan, V. S. Y. (2002). Personality change over 40 years of adulthood: Hierarchical linear modeling analyses of two longitudinal samples. Journal of Personality and Social Psychology, 83, 752-766.

Hill, P. L., Turiano, N. A., Hurd, M. D., Mroczek, D. K., \& Roberts, B. W. (2011). Conscientiousness and longevity: An examination of possible mediators. Health Psychology, 30, 536-541.

Hogan, J., \& Holland, B. (2003). Using theory to evaluate personality and job-performance relations: A socioanalytic perspective. Journal of Applied Psychology, 88, 100-112.

Hogan, R. (2005). In defense of personality measurement: New wine for old whiners. Human Performance, 18, 331-341.

Judge, T. A., Bono, J. E., Ilies, R., \& Gerhardt, G. W. (2002). Personality and leadership: A qualitative and quantitative review. Journal of Applied Psychology, 87, 765-780.

Judge, T. A., \& Ilies, R. (2002). Relationship of personality to performance motivation: A meta-analytic review. Journal of Applied Psychology, 87, 797-807.

Kanfer, R., Wanberg, C. R., \& Kantrowitz, T. M. (2001). Job search and employment: A personality - Motivational analysis and meta-analytic review. Journal of Applied Psychology, 86, 837-855. 
King, L. A., Hicks, J. A., Krull, J. L., \& Del Gaiso, A. K. (2006). Positive affect and the experience of meaning in life. Journal of Personality and Social Psychology, 90, 179196.

Lahey, B. B. (2009). Public health significance of neuroticism. American Psychologist, 64, 241-256.

Layard, R. (2006). Health policy: The case for psychological treatment centres. British Medical Journal, 332, 1030-1032.

Losoncz, I. (2009). Personality Traits in HILDA: Australian Social Policy No. 8.

Lucas, R. E., \& Donnellan, M. B. (2011). Personality development across the life span: Longitudinal analyses with a national sample from Germany. Journal of Personality and Social Psychology, 101, 847-861.

Lucas, R. E., \& Dyrenforth, P. S. (2006). Does the existence of social relationships matter for subjective well-being? In E. J. Finkel \& K. D. Vohs (Eds.), Self and Relationships: Connecting Intrapersonal and Interpersonal Processes. New York: NY: Guildford Press.

Lykken, D., \& Tellegen, A. (1996). Happiness is a stochastic phenomenon. Psychological Science, 7, 186-189.

Lyubomirsky, S., King, L., \& Diener, E. (2005). The benefits of frequent positive affect: Does happiness lead to success? Psychological Bulletin, 131, 803-855.

MacLean, K. A., Johnson, M. W., \& Griffiths, R. R. (in press). Mystical experiences occasioned by the hallucinogen psilocybin lead to increases in the personality domain of openness Journal of Psychopharmacology.

Matzler, K., Renzl, B., Muller, J., Herting, S., \& Mooradian, T. A. (2008). Personality traits and knowledge sharing. Journal of Economic Psychology, 29, 301-313.

McCrae, R. R., \& Costa, P. T. (1987). Validation of the 5-factor model of personality across instruments and observers. Journal of Personality and Social Psychology, 52, 81-90. 
McCrae, R. R., \& Costa, P. T. (1997). Personality trait structure as a human universal. American Psychologist, 52, 509-516.

McGregor, I., \& Little, B. R. (1998). Personal projects, happiness, and meaning: On doing well and being yourself. Journal of Personality and Social Psychology, 74, 494-512.

Mueller, G., \& Plug, E. J. S. (2006). Estimating the effect of personality on male and female earnings. Industrial \& Labor Relations Review, 60, 3-22.

Neyer, F. J., \& Asendorpf, J. B. (2001). Personality-relationship transaction in young adulthood. Journal of Personality and Social Psychology, 81, 1190-1204.

Nyhus, E. K., \& Pons, E. (2005). The effects of personality on earnings. Journal of Economic Psychology, 26, 363-384.

O'Cleirigh, C., Ironson, G., Weiss, A., \& Costa, P. T. (2007). Conscientiousness predicts disease progression (CD4 number and viral load) in people living with HIV. Health Psychology, 26, 473-480.

O'Connor, D. B., Conner, M., Jones, F., McMillan, B., \& Ferguson, E. (2009). Exploring the benefits of conscientiousness: An investigation of the role of daily stressors and health behaviors. Annals of Behavioral Medicine, 37, 184-196.

Oswald, A. J., \& Powdthavee, N. (2008a). Death, happiness, and the calculation of compensatory damages. Journal of Legal Studies, 37, 217-251.

Oswald, A. J., \& Powdthavee, N. (2008b). Does happiness adapt? A longitudinal study of disability with implications for economists and judges. Journal of Public Economics, 92, 1061-1077.

Pai, M., \& Carr, D. (2010). Do personality traits moderate the effect of late-life spousal loss on pychological distress? Journal of Health and Social Behavior, 51, 183-199.

Paunonen, S. V., \& Ashton, M. C. (2001). Big five factors and facets and the prediction of behavior. Journal of Personality and Social Psychology, 81, 524-539.

Piedmont, R. L. (2001). Cracking the plaster cast: Big five personality change during intensive outpatient counseling. Journal of Research in Personality, 35, 500-520. 
Plumper, T., \& Troeger, V. E. (2007). Efficient estimation of time-invariant and rarely changing variables in finite sample panel analyses with unit fixed effects. Political Analysis, 15, 124-139.

Powdthavee, N. (2008). Putting a price tag on friends, relatives, and neighbours: Using surveys of life satisfaction to value social relationships. Journal of Socio-Economics, $37,1459-1480$.

Proudfoot, J. G., Corr, P. J., Guest, D. E., \& Dunn, G. (2009). Cognitive-behavioural training to change attributional style improves employee well-being, job satisfaction, productivity, and turnover. Personality and Individual Differences, 46(2), 147-153.

Roberts, B. W. (1997). Plaster or plasticity: Are adult work experiences associated with personality change in women? Journal of Personality, 65, 205-232.

Roberts, B. W., \& Bogg, T. (2004). A longitudinal study of the relationships between conscientiousness and the social-environmental factors and substance-use behaviors that influence health. Journal of Personality, 72, 325-353.

Roberts, B. W., Caspi, A., \& Moffitt, T. E. (2003). Work experiences and personality development in young adulthood. Journal of Personality and Social Psychology, 84, $582-593$.

Roberts, B. W., Helson, R., \& Klohnen, E. C. (2002). Personality development and growth in women across 30 years: Three perspectives. Journal of Personality, 70, 79-102.

Roberts, B. W., Walton, K. E., \& Viechtbauer, W. (2006a). Patterns of mean-level change in personality traits across the life course: A meta-analysis of longitudinal studies. Psychological Bulletin, 132, 1-25.

Roberts, B. W., Walton, K. E., \& Viechtbauer, W. (2006b). Personality traits change in adulthood: Reply to Costa and McCrae (2006). Psychological Bulletin, 132, 29-32.

Roberts, B. W., Wood, D., \& Caspi, A. (Eds.). (2008). The development of personality traits in adulthood (3rd ed.). New York: Guilford. 
Ryff, C. D., Love, G. D., Urry, H. L., Muller, D., Rosenkranz, M. A., Friedman, E. M., et al. (2006). Psychological well-being and ill-being: Do they have distinct or mirrored biological correlates? Psychotherapy and Psychosomatics, 75, 85-95.

Schmitt, P., Shupp, R., Swope, K., \& Mayer, J. (2008). Pre-commitment and personality: Behavioral explanations in ultimatum games. Journal of Economic Behavior \& Organization, 66, 597-605.

Schwarz, N., \& Clore, G. L. (1983). Mood, misattribution, and judgments of well-being informative and directive functions of affective states. Journal of Personality and Social Psychology, 45, 513-523.

Schwarz, N., Strack, F., \& Mai, H. P. (1991). Assimilation and contrast effects in part-whole question sequences - a conversational logic analysis. Public Opinion Quarterly, 55, 323.

Scollon, C. N., \& Diener, E. (2006). Love, work, and changes in extraversion and neuroticism over time. Journal of Personality and Social Psychology, 91, 1152-1165.

Semykina, A., \& Linz, S. J. (2007). Gender differences in personality and earnings: Evidence from Russia. Journal of Economic Psychology, 28, 387-410.

Srivastava, S., Angelo, K. M., \& Vallereux, S. R. (2008). Extraversion and positive affect: A day reconstruction study of person-environment transactions. Journal of Research in Personality, 42, 1613-1618.

Srivastava, S., John, O. P., Gosling, S. D., \& Potter, J. (2003). Development of personality in early and middle adulthood: Set like plaster or persistent change? Journal of Personality and Social Psychology, 84, 1041-1053.

Steel, P., Schmidt, J., \& Shultz, J. (2008). Refining the relationship between personality and subjective well-being. Psychological Bulletin, 134, 138-161.

Swope, K., Cadigan, J., Schmitt, P., \& Shupp, R. (2008). Personality preferences in laboratory economics experiments. The Journal of Socio-Economics, 37, 998-1009. 
Watson, D., \& Humrichouse, J. (2006). Personality development in emerging adulthood: Integrating evidence from self-ratings and spouse ratings. Journal of Personality and Social Psychology, 91, 959-974.

Winkelmann, L., \& Winkelmann, R. (2008). Personality, work, and satisfaction: Evidence from the German Socio-Economic Panel. The Journal of Positive Psychology, 3, 266275.

Wood, A. M., Joseph, S., \& Maltby, J. (2008). Gratitude uniquely predicts satisfaction with life: Incremental validity above the domains and facets of the five factor model. Personality and Individual Differences, 45, 49-54.

Worthington, R. L., \& Whittaker, T. A. (2006). Scale development research - A content analysis and recommendations for best practices. Counseling Psychologist, 34, 806838. 
Personality change and well-being 32

Table 1: Summary statistics across a population measured at two time points $(\mathrm{N}=17250)$ - non-standardised

\begin{tabular}{|c|c|c|c|c|}
\hline Variable: & & Mean & "Standard Deviation & Between-to-Within Ratio \\
\hline Life Satisfaction & $\begin{array}{c}\text { Overall } \\
\text { Between } \\
\text { Within }\end{array}$ & 7.92 & $\begin{array}{l}1.41 \\
1.23 \\
0.69\end{array}$ & 1.77 \\
\hline Openness to Experiences & $\begin{array}{c}\text { Overall } \\
\text { Between } \\
\text { Within }\end{array}$ & 4.19 & $\begin{array}{l}1.06 \\
0.98 \\
0.41\end{array}$ & 2.37 \\
\hline Conscientiousness & $\begin{array}{c}\text { Overall } \\
\text { Between } \\
\text { Within }\end{array}$ & 5.13 & $\begin{array}{l}1.02 \\
0.94 \\
0.40\end{array}$ & 2.33 \\
\hline Extroversion & $\begin{array}{c}\text { Overall } \\
\text { Between } \\
\text { Within }\end{array}$ & 4.40 & $\begin{array}{l}1.07 \\
1.00 \\
0.38\end{array}$ & 2.60 \\
\hline Agreeableness & $\begin{array}{c}\text { Overall } \\
\text { Between } \\
\text { Within }\end{array}$ & 5.38 & $\begin{array}{l}0.91 \\
0.81 \\
0.41\end{array}$ & 1.99 \\
\hline Neuroticism & $\begin{array}{c}\text { Overall } \\
\text { Between } \\
\text { Within }\end{array}$ & 5.25 & $\begin{array}{l}1.07 \\
0.97 \\
0.45\end{array}$ & 0.98 \\
\hline $\begin{array}{l}\text { Household Income } \\
\text { (Australian Dollars) }\end{array}$ & $\begin{array}{c}\text { Overall } \\
\text { Between } \\
\text { Within }\end{array}$ & 87,289 & $\begin{array}{l}75,658 \\
67,409 \\
34,358\end{array}$ & 2.20 \\
\hline Age & $\begin{array}{c}\text { Overall } \\
\text { Between } \\
\text { Within }\end{array}$ & 46.51 & $\begin{array}{c}17.24 \\
17.13 \\
2.00\end{array}$ & 8.62 \\
\hline Female & $\begin{array}{c}\text { Overall } \\
\text { Between } \\
\text { Within }\end{array}$ & 0.54 & $\begin{array}{c}0.50 \\
0.50 \\
\mathrm{n} / \mathrm{a}\end{array}$ & $\mathrm{n} / \mathrm{a}$ \\
\hline Adults in Household & $\begin{array}{c}\text { Overall } \\
\text { Between } \\
\text { Within }\end{array}$ & 2.21 & $\begin{array}{l}0.96 \\
0.86 \\
0.44\end{array}$ & 1.97 \\
\hline Children in Household & $\begin{array}{c}\text { Overall } \\
\text { Between } \\
\text { Within }\end{array}$ & 0.58 & $\begin{array}{l}0.99 \\
0.91 \\
0.38\end{array}$ & 2.42 \\
\hline Married & $\begin{array}{c}\text { Overall } \\
\text { Between } \\
\text { Within }\end{array}$ & 0.56 & $\begin{array}{l}0.50 \\
0.47 \\
0.15\end{array}$ & 3.16 \\
\hline Separated & $\begin{array}{c}\text { Overall } \\
\text { Between } \\
\text { Within }\end{array}$ & 0.03 & $\begin{array}{l}0.17 \\
0.15 \\
0.09\end{array}$ & 1.55 \\
\hline Divorced & $\begin{array}{c}\text { Overall } \\
\text { Between } \\
\text { Within }\end{array}$ & 0.09 & $\begin{array}{l}0.29 \\
0.28 \\
0.10\end{array}$ & 2.78 \\
\hline Widowed & $\begin{array}{c}\text { Overall } \\
\text { Between } \\
\text { Within }\end{array}$ & 0.05 & $\begin{array}{l}0.22 \\
0.21 \\
0.06\end{array}$ & 3.30 \\
\hline Unemployed & $\begin{array}{c}\text { Overall } \\
\text { Between } \\
\text { Within }\end{array}$ & 0.02 & $\begin{array}{l}0.15 \\
0.12 \\
0.19\end{array}$ & 1.14 \\
\hline
\end{tabular}


Personality change and well-being 33

Table 2: Correlation matrix of life satisfaction, personality traits and demographic characteristics

\begin{tabular}{|c|c|c|c|c|c|c|c|c|c|c|c|c|c|c|c|}
\hline 1. Life Satisfaction & $\begin{array}{l}1 . \\
-\end{array}$ & 2. & 3. & 4. & 5. & 6. & 7. & 8. & 9. & 10. & 11. & 12. & 13. & 14. & 15. \\
\hline 2. Openness to Experiences & $-0.06^{* *}$ & - & & & & & & & & & & & & & \\
\hline 3. Conscientiousness & $0.17 * *$ & $0.07 * *$ & - & & & & & & & & & & & & \\
\hline 4. Extroversion & $0.15 * *$ & $0.07 * *$ & $0.13 * *$ & - & & & & & & & & & & & \\
\hline 5. Agreeableness & $0.16^{* *}$ & $0.27 * *$ & $0.29 * *$ & $0.16 * *$ & - & & & & & & & & & & \\
\hline 6. Neuroticism & $0.26 * *$ & $-0.22 * *$ & $0.30 * *$ & $0.18 * *$ & $0.15 * *$ & - & & & & & & & & & \\
\hline $\begin{array}{l}\text { 7. Household Income } \\
\text { (Australian Dollars) }\end{array}$ & $0.06 * *$ & $0.05 * *$ & $0.04 * *$ & $0.05^{* *}$ & $-0.02 * *$ & -0.01 & - & & & & & & & & \\
\hline 8. Age & $0.11 * \star$ & $-0.12 * *$ & $0.17 * *$ & $-0.08 * *$ & $0.08 * *$ & $0.26 * *$ & $-0.20 * *$ & - & & & & & & & \\
\hline 9. Female & $0.03 * *$ & $-0.05^{* *}$ & $0.09 * *$ & $0.12 * *$ & $0.25 * *$ & $0.05 * *$ & $-0.04 * *$ & -0.00 & - & & & & & & \\
\hline 10. Adults in Household & $0.05 * \star$ & -0.01 & $-0.06^{* *}$ & $0.02 *$ & $-0.03 * *$ & $-0.07 * *$ & $0.37 * *$ & $-0.23 * *$ & $-0.03 * *$ & - & & & & & \\
\hline 11. Children in Household & $-0.03 * *$ & -0.01 & $-0.06^{* *}$ & $0.03 * *$ & $-0.04 * *$ & $-0.08 * *$ & $0.12 * *$ & $-0.31 * *$ & $0.02 *$ & $0.08 * *$ & - & & & & \\
\hline 12. Married & $0.12 * *$ & $-0.08 * *$ & $0.10 * *$ & -0.00 & $0.03 * *$ & $0.07 * *$ & $0.16 * *$ & $0.26 * *$ & $-0.05 * *$ & $0.22 * *$ & $0.18 * *$ & - & & & \\
\hline 13. Separated & $-0.10 * *$ & $0.03 * *$ & -0.00 & 0.00 & $0.03 * *$ & $-0.02 *$ & $-0.05^{* *}$ & $0.03 * *$ & -0.00 & $-0.11 * *$ & -0.00 & $-0.20 * *$ & - & & \\
\hline 14. Divorced & $-0.08 * *$ & $0.06 * *$ & $0.04 * *$ & 0.01 & $0.05 * *$ & $0.03 * *$ & $-0.10^{* *}$ & $0.12 * *$ & $0.05^{* *}$ & $-0.18 * *$ & $-0.07 * *$ & $-0.36^{* *}$ & $-0.06 * *$ & - & \\
\hline 15. Widowed & $0.05 * *$ & $-0.09 * *$ & $0.04 * *$ & $-0.02 *$ & $0.04 * *$ & $0.13 * *$ & $-0.16^{* *}$ & $0.35^{* *}$ & $0.12 * *$ & $-0.23 * *$ & $-0.12 * *$ & $-0.26^{* *}$ & $-0.04 * *$ & $-0.08 * *$ & - \\
\hline 16. Unemployed & $-0.05 * *$ & $0.03 * *$ & $-0.05^{* *}$ & -0.01 & -0.01 & $-0.05^{* *}$ & $-0.03^{* *}$ & $-0.11^{* *}$ & -0.01 & $0.04 * *$ & 0.01 & $-0.08^{* *}$ & 0.00 & 0.01 & $-0.03 * *$ \\
\hline
\end{tabular}


Table 3: Ordinary least squares regressions predicting life satisfaction from economic indicators and personality variables

(1) (2) (3)

Life Satisfaction (standardised)

Dependent Variable:

Independent Variables:

Year Dummy

Yes

No

Yes

Regional dummies

Yes

No

Yes

Additional controls (age, age

squared, gender, size of the

Yes

No

Yes household, education, marital status)

Log of Household Income

0.144

$(0.011)^{* *}$

Household Income (\$1000)

Unemployed

Openness (standardised)

Conscientiousness (standardised)

Extroversion (standardised)

Agreeableness (standardised)

Neuroticism (standardised)

Constant
$-0.897$

$(0.172)^{* *}$

$-0.184$

$(0.172)^{* *}$

$-0.062$

$(0.008)^{* *}$

0.073

$(0.008)^{* *}$

0.092

$(0.007)^{* *}$

0.111

$(0.008)^{* *}$

0.194

$(0.008)^{* *}$

0.00

$(0.007)^{* *}$
0.131

$(0.011)^{* *}$

\section{(3)}

. 
Table 4: Fixed effects regressions predicting life satisfaction from economic indicators and personality variables

\begin{tabular}{lcccc}
\hline \hline & $(1)$ & $(2)$ & $(3)$ & $(4)$ \\
Dependent Variable: & \multicolumn{4}{c}{ Life Satisfaction } \\
(standardised)
\end{tabular}

Standard errors in parenthesis * significant at 5\%; ** significant at 1\% 


\section{University Library}

\section{- M M I N E R VA \\ A gateway to Melbourne's research publications}

Minerva Access is the Institutional Repository of The University of Melbourne

Author/s:

Boyce, CJ;Wood, AM;Powdthavee, N

Title:

Is Personality Fixed? Personality Changes as Much as "Variable" Economic Factors and More Strongly Predicts Changes to Life Satisfaction

Date:

2013-03-01

\section{Citation:}

Boyce, C. J., Wood, A. M. \& Powdthavee, N. (2013). Is Personality Fixed? Personality Changes as Much as "Variable" Economic Factors and More Strongly Predicts Changes to Life Satisfaction. SOCIAL INDICATORS RESEARCH, 111 (1), pp.287-305. https:// doi.org/10.1007/s11205-012-0006-z.

Persistent Link:

http://hdl.handle.net/11343/282950 